
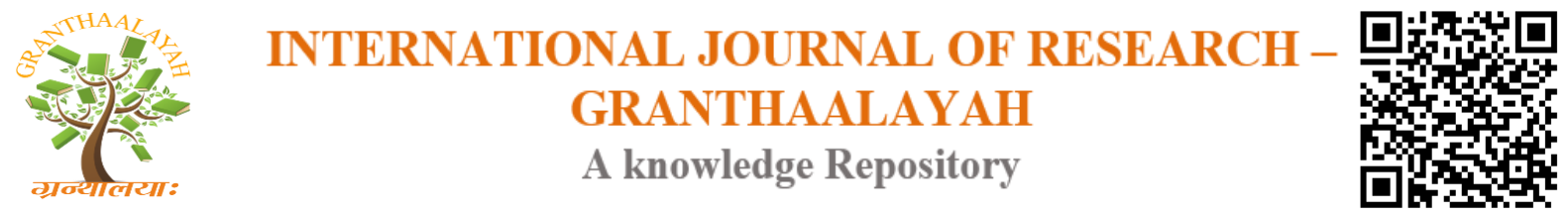

Science

\title{
CAROTID BODY TUMOR MASQUERADING AS AN ISOLATED SUBMANDIBULAR LYMPH NODE- A CASE REPORT AND LITERATURE REVIEW
}

\author{
Patrick Harnarayan ${ }^{1}$, Shariful Islam ${ }^{* 2}$, Christi Ramsingh ${ }^{2}$, Purandath Lall ${ }^{2}$ \\ ${ }^{1}$ Department of Clinical Surgical Sciences, University of the West Indies, St Augustine, \\ TRINIDAD AND TOBAGO \\ ${ }^{2}$ Department of General Surgery, San Fernando Teaching Hospital, \\ TRINIDAD AND TOBAGO
}

DOI: https://doi.org/10.29121/granthaalayah.v4.i11.2016.2416

\section{ABSTRACT}

Carotid body tumors (CBT) are very rare tumors and CBT masquerading as a submandibular lymph node are even rarer. The authors report a case of a middle aged male who was referred to the Otolaryngology department for investigation of a suspected/ apparent left submandibular lymph node. It was slow growing in nature, painless and firm to the touch but was otherwise asymptomatic. Given this presentation and his history of smoking two (2) packs of cigarettes a day for fifty-three (53) years a malignancy of the head and neck area was suspected. A Fine Needle Aspiration Cytology (FNAC) was done at his first visit and this was negative for malignancy. A Computed Tomography (CT) scan of the neck revealed a mass within the carotid sheath with the characteristic Lyre sign: the splaying of the internal and external carotid arteries typical of a paraganglioma or chemodectoma. Based on the recommendations of Shamblin, this case was classified as a Shamblin I, i.e. a perfect candidate for surgical resection. After adequate preparation, informed consent and further imaging, the tumor was resected an uneventful recovery was to be in keeping with the dictum of the Shamblin classification. The histology was reported as a Paraganglioma with no atypical features. We think this is the first reported case of CBT from the Caribbean countries.

Keywords:

Cervical lymph node; Paraganglioma; Chemodectoma; Shamblin; Carotid Body Tumor.

Cite This Article: Patrick Harnarayan, Shariful Islam, Christi Ramsingh, and Purandath Lall, "CAROTID BODY TUMOR MASQUERADING AS AN ISOLATED SUBMANDIBULAR LYMPH NODE- A CASE REPORT AND LITERATURE REVIEW” International Journal of Research - Granthaalayah, Vol. 4, No. 11 (2016): 13-22. 


\section{INTRODUCTION}

Carotid bodies are ellipsoid structures that lie within the adventitia of the carotid vessels, especially at the carotid bifurcation. They contain chemoreceptor cells, which physiologically mean that they are involved in the reflex control of respiration, heart rate and blood pressure via the chemical composition of blood.

Carotid body tumors (CBT) are rare entities and yet the most common form of head and neck paragangliomas. Originally termed Chemodectomas, these tumors are now accepted under the umbrella category of paragangliomas which is a reflection of their tissue of origin. CBTs are commonly found as lateral neck masses lying within the carotid triangle.

Upon their detection, surgery is generally accepted as the treatment of choice. These tumors are categorized by the Shamblin classification which predicts resectability, depending on the tumor size. However, surgical resection is fraught with the possibility of cranial nerve injury so accurate preoperative imaging is essential.

We present a fit middle aged male smoker referred with an asymptomatic slow growing left carotid triangle mass.

\section{CASE REPORT}

We report the case of a 67 year old 50 pack-year smoker (for the last 53 years) male patient who presented with a submandibular swelling which he had noted 3 months previously. It was painless, slow growing and firm to the touch and worrying enough for the patient to seek an opinion at the emergency department and then receive an urgent consultation with the Otolaryngology team on call.

He was thought initially to have an enlarged cervical lymph node and had a Fine Needle Aspiration Cytology (FNAC) done and a CT scan of neck and chest was requested. Ten months previously he had been admitted to the internal medical service with an episode of syncope after feeling warm and sweaty. His vital signs then, cardiac clinical testing and lab investigations were all within normal limits. The CT brain and EEG ordered at that time were grossly unremarkable and he did not recall having a neck mass of any sort. He has had no further episodes of syncope since that admission.

Admittedly he had a history of smoking cigarettes amounting to approximately 50 pack years, but was asymptomatic, and his history was negative for trauma, infection or other sinister red flags There was no positive family history of endocrine or oncological disease, his performance status was ECOG 0, not having changed since the discovery of this mass. He was normotensive, suffered no palpitations and none of his blood investigations indicated that this was an active endocrine tumor.

Clinical examination revealed that his vital signs were within normal limits. On palpation, there was an approximately $5 \times 6 \mathrm{~cm}$ non pulsatile, firm, fixed mass in the left carotid triangle. There was no tenderness on palpation nor was there a bruit on auscultation. Of note, the mass, on 
palpation, was barely mobile from side to side but no motion was possible in the vertical plane, i.e., Fontaine's sign was demonstrated. His blood parameters were within normal limits. Fine needle aspiration cytology of the mass was performed which revealed no malignant cells.

Computed Tomography of the neck showed a heterogeneously enhancing mass in the left carotid sheath which measured $4.5 \times 3.5 \mathrm{~cm}$. The mass displaced the carotid vessels anteriorly but they were otherwise normal. There was neither cervical lymphadenopathy nor other masses and a Carotid Doppler, which was also requested, showed a 41 x $27 \mathrm{~mm}$ mass with an inhomogeneous internal echo pattern noted adjacent to the lateral aspect of the left internal carotid artery. There was no increased perfusion noted in this mass and the carotid vessels showed normal patency.

After counseling, he was prepared for the surgical resection after being made aware that the incidence of cranial nerve injury was significant. In addition, there was a risk of a cerebrovascular attack (CVA) as well as wide blood pressure variations despite this mass not being classified as an active tumor. He successfully achieved smoking cessation pre operatively and medical clearance was obtained. An ECHO Cardiogram was requested, and this revealed that his ejection fraction was more than $70 \%$. A follow up CT neck was ordered to reveal if there was any change in size or growth pattern such as vessel encasement or lymphadenopathy.

This demonstrated a 3.5 (CC) x 3.0 (AP) x 2.8 (TR) $\mathrm{cm}$ well circumscribed mass in the left carotid space at the $\mathrm{C} 2$ to $\mathrm{C} 4$ level [Fig-1]. The mass was heterogeneously enhancing with a central area of necrosis and hemorrhage. The mass compressed but did not invade the left internal and external carotid arteries. There was characteristic splaying of the left internal and external carotid arteries secondary to the mass i.e., Lyre's sign. The mass also led to compression and displacement of the left internal jugular vein. There was no invasion of bone and the rest of the study was unremarkable. MR imaging was unavailable at that time. The patient was prepared for surgery.

At surgery the patient was given a general anesthetic as planned, placed with the head at 45 degrees to the contralateral side, and after cleaning and draping, an incision was made along the anterior border of the sternocleidomastoid muscle and dissection carried out down to the internal jugular vein.

Intraoperatively, the internal jugular vein was displaced, the large mass was noted [Fig-2] in relation to the carotid sheath. The carotid vessels were isolated and slung with vascular loops and using a sub adventitial plane the mass was dissected free from a position posterior to the vessels in the sheath and not actually at the bifurcation as suspected from viewing the images. Venous feeding vessels were divided between ligatures, the hypoglossal nerve was identified, and sharp dissection was utilized with minimal diathermy to free up the tumor mass. It was dissected free of the surrounding tissue distally then proximally and removed [Fig-3]. The tumor was oriented and sent for histopathological examination. At surgery the mass was confirmed as a Shamblin's Grade I tumor, which corresponded to the radiological findings. There was minimal blood loss throughout the entire procedure and there was no blood pressure fluctuation during the procedure. 
Postoperatively there was a favorable outcome, as he recovered without any nerve palsies, or other loss of function. There was no notable change in this patient's blood pressure trend either during surgery or in the post-operative phase. He was discharged and seen in clinic for follow up surveillance. His 2 year follow up was negative for symptoms as well as tumor regrowth.

Histopathological report revealed that the mass was $5.0 \mathrm{~cm}$ x $3.0 \mathrm{~cm} \times 2.5 \mathrm{~cm}$ with hemorrhagic cystic cavities but no atypical features such as increased mitoses or necrosis. The tumor was identified as a paraganglioma [Fig-4 \&5] and there were no features of malignant transformation.

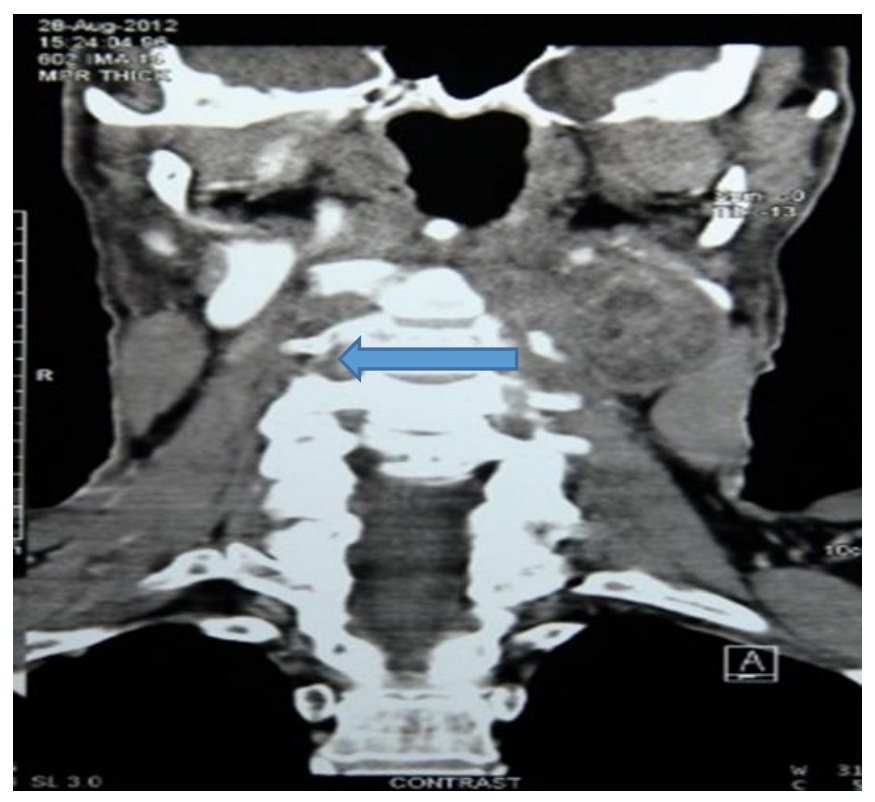

Figure 1: Coronal section of CT Neck with IV Contrast showing a hyper vascular mass at the left sided bifurcation of the internal and external carotid arteries. Lyre's sign can be observed here (blue arrow).

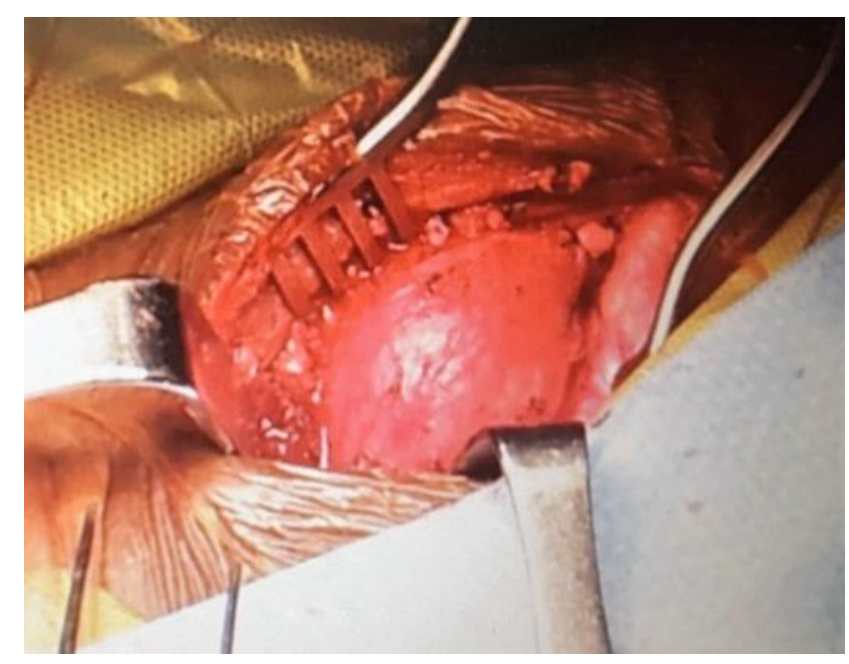

Figure 2: Intra operative photograph of the left paraganglioma lying nestled between the internal and external carotid arteries. 


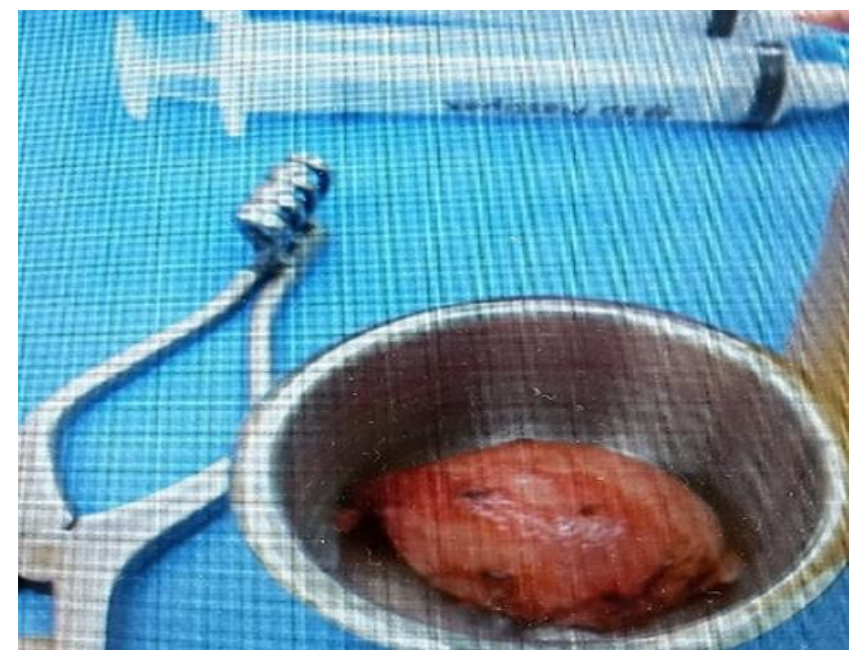

Figure 3: A photograph of the Carotid Body Tumor showing its Pseudo capsule

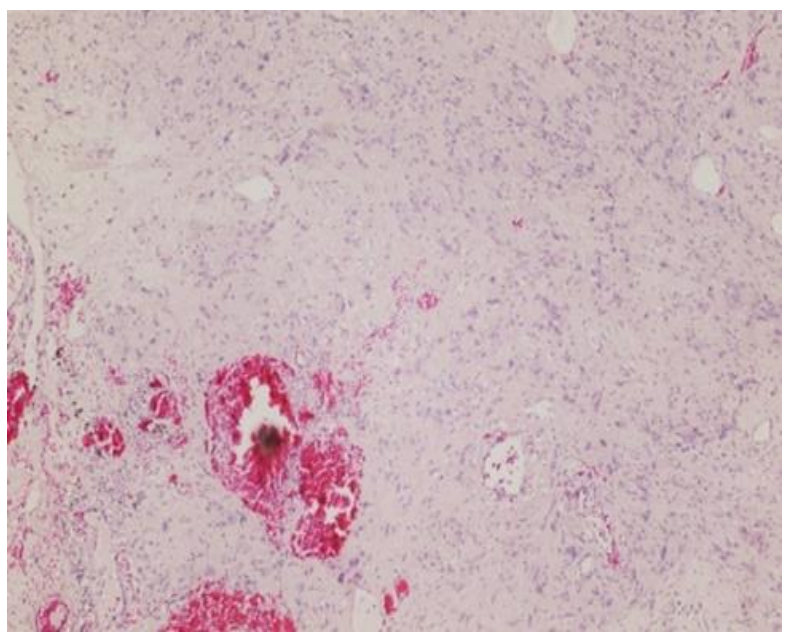

Figure 4: A photomicrograph of an $\mathrm{H}$ and $\mathrm{E}$ stain of the paraganglioma at $40 \mathrm{x}$ magnification. There is a distinctively spherical nesting pattern of neoplastic chief cells that lies within a prominent vascular network.

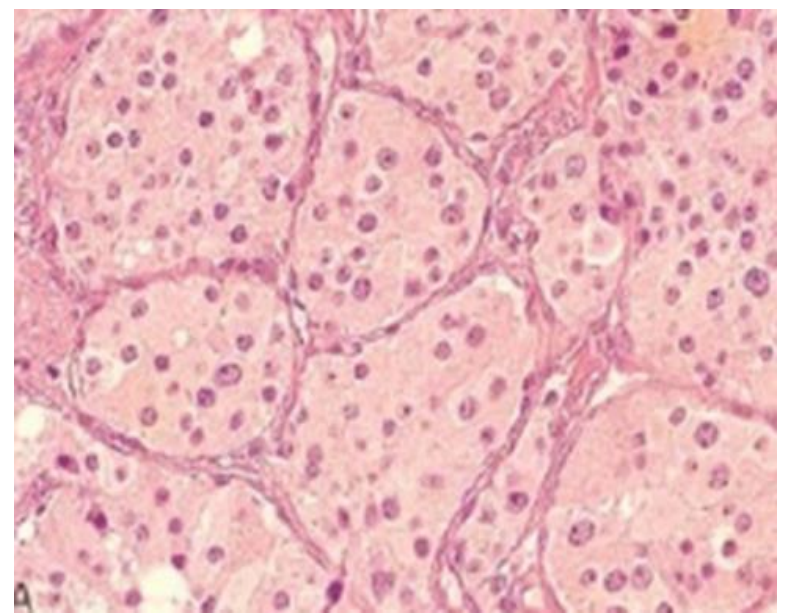

Figure 5: A high powered photomicrograph of the paraganglioma, depicting the Zellballen or spherical nesting pattern. 


\section{DISCUSSIONS}

Paragangliomas are neuroectodermally derived tumors that originate from the paravertebral, parasympathetic or sympathetic ganglia (paraganglia) [1]. The parasympathetic derived tumors occur throughout the body from the base of skull to the pelvic region with the majority located in the head and neck region. Head and neck paragangliomas are slow growing hyper vascular tumors 2 typically found in the carotid body, jugular bulb, tympanic nerves and aortic glomus with the carotid body being the most common site [2, 3, 4]. The carotid body was first described in 1743 by von Haller5, but the first case of a tumor was reported in 1891 by Marchand [5] and later (1950) Mulligan used the term chemodectoma [6 ] to characterize a neoplasm consisting of chemoreceptor cells. Carotid body tumors (CBTs) are rare, with a prevalence of 1-2 per 100,000 $[3,4]$ and may be divided into functioning and non-functioning tumors according to their ability to secrete catecholamines. They can be further subdivided into sporadic, familial and hyperplastic types depending on their geographic location with the sporadic subtype being the most commonly seen [7]. In the familial type, which is autosomal dominant and usually bilateral, the age of onset is earlier [8] but there is a female preponderance in the sporadic form, and interestingly, this ratio increases with altitude [9].

The etiology of these tumors is largely unknown but there may be a molecular basis and patients with bilateral disease and a family history may have germline mutations of the succinyl dehydrogenase gene (SDH) subunits SDHB, SDHC and SDHD [10]. They can be hereditary and associated with genetic syndromes such as Von Hippel-Lindau and Von Recklinghausen diseases as well as MEN 2A and 2B syndromes.

CBTs arise at the medial aspect of the carotid bifurcation, emerging within the vascular adventitia [5] and patients mainly present with a slow-growing painless lateral neck mass [11, 12] located anterior to the sternocleidomastoid muscle [13]. On examination, the neck mass which is usually located just below the angle of the mandible in the carotid sub triangle of the anterior triangle, sometimes appears pulsatile (it can transmit the carotid pulse) and can also be mistaken for lymph nodes (in this patient) or even salivary gland tumors [14]. Fontaine's sign, used to describe the movement of the mass in different planes, is the ability to move the tumor in a lateral but not in a vertical plane [15] . This is due to its attachment to the carotid vessels as it arises from their adventitia.

Active carotid body tumors may cause catecholamine hypersecretion presenting with hypertension that fluctuates, palpitations, blushing, as well as diarrhea but can present in other ways including Cerebrovascular Attacks (CVAs-ischemic strokes) and Transient Ischemic Attacks $[16,17]$. It is interesting to note that CBT resection may also have a beneficial effect with sustained reduction of blood pressure in hypertensive patients [18].

All Carotid body tumors (CBTs) have malignant potential and it is not possible to determine malignant change based on the histology of the lesion [1]. Indeed there are no clear histological features that would differentiate it from a benign tumour [13] and there is no correlation between histology and clinical behavior [19]. Spread to local tissue, regional lymph nodes and distal spread characterize the malignant lesion. Sometimes large $(5-8 \mathrm{~cm})$ isolated malignant tumors 
may occur, presenting as hard, non-tender, immobile masses in the upper aspect of the neck with lymph node involvement [20].

CBTs are vascular lesions and this is the basis of their imaging1. Radiological investigations are multi-tiered with the initial, routine investigation being an ultrasound scan of the neck to characterize the swelling, define the anatomy of the area, and to determine whether it is solid or cystic thus enabling careful fine needle aspiration cytology to be done. A color-coded probe (Duplex Scan) will show the vascularity of the mass and provide the most information concerning the diagnosis especially its relation to the large neck vessels that it abuts [21].

Angiography of the carotid tree is the diagnostic test of choice for imaging the lesion1 demonstrating their blood supply [13], Computed Tomography (CT) scan with contrast of the neck will reveal a hyper vascular mass at the carotid bifurcation with splaying of the internal and external carotid arteries by the lesion (Lyre's sign) a feature that is usually pathognomic of CBTs [22]. MR angiography typically shows a "salt and pepper" appearance on T2 weighted imaging where the "pepper" refers to low signal flow voids due to the numerous surface vessels and the "salt" refers to the high foci signal of hemorrhage or low flow [1]. MR angiography is useful for more information on the vascularity of the mass as well as any feeder vessels for purposes of angio-embolization, and also to rule out possible encasement or invasion of the carotid vessels in the case of malignant lesions. An enlarging CBT causes encasement, not narrowing, of the carotid vessels. Indium 111 Octreotide, a somatostatin analogue, is a newer nuclear imaging tool available (neuroendocrine tumors have receptors for somatostatin) for detecting presence of multi-centric or metastatic paragangliomas [1].

Preoperative imaging may sometimes predict surgical complications after tumor resection [23]. Cranial nerve and carotid artery injury as well as major carotid artery repair were associated with "high-lying" CBTs when the distance from the tip of the $\mathrm{C} 2$ dens to the superior aspect of the CBT was found to be less than 3 centimeters (dens-CBT $=1.8-2.9, \mathrm{p}<0.01$ ) using preoperative computed tomography (CT) and magnetic resonance imaging (MRI) [24].

Shamblin's classification of carotid body tumors in 1971 [25] has been widely hailed as a pivotal point in the management of these tumours [3]. This classification is used to predict the resectability of the tumors based on size. Shamblin group I tumors are small, meaning they can be easily dissected from the vessels [13]. Group II are medium sized tumors, closely associated with the vessels and are adherent, partially surrounding the vessels, but able to be removed with gentle sub-adventitial dissection and group III are large tumors that encase the vessels. These usually require vessel resection and reconstruction with vein grafts. USS and MR angiography can positively predict the Shamblin classification [19, 26, 27].

Preoperative embolization is indicated in large tumors which include Shamblin II or greater [4]. Since Shamblin III tumor surgery often leads to an increased risk of intra- and postoperative morbidity, its role is to reduce size and vascularity of the gland allowing for easier dissection hence reducing postoperative complications [28, 29]. Can the Shamblin classification predict outcomes? Shamblin class was a good predictor of blood loss, operative time and degree of resectability, but not post-operative complications [29]. 
Although surgery is the mainstay of treatment there are studies looking at the benefits of conservative management in selected cases [3] especially in patients who are not fit for surgery. The role of radiotherapy in treatment had been previously regarded as poor, but recent research points to reports of good responses [9] for large, recurrent and malignant paragangliomas, especially in those with regional lymph node metastases [13]. Surgery and radiation therapy appear to work well for isolated metastases [20]. The radiotherapy works by eradicating lymphatic disease that may not be grossly evident and prolonging local control after surgery, which thus limits further spread [30].

\section{CONCLUSIONS}

This is a unique case of a middle aged heavy smoking male with an asymptomatic unilateral neck mass for months thought to be initially, a cervical lymph node. There was a negative FNAC and Computed Tomography suggested evidence of a possible paraganglioma. It was surgically removed and did not, despite the duration of his history, provide any endocrine or vascular difficulties in its resection. Two year follow up has revealed no delayed complications and no recurrence. It is important to keep this differential in mind for lateral painless neck masses in the carotid triangle. This is the first reported case in our population, as there is no local literature on the topic currently.

\section{LEARNING POINTS}

1) Carotid body tumors are very rare.

2) Carotid body tumors presenting as an isolated submandibular lymph node are also exceedingly rare.

3) High index of suspicion should be kept in the differential diagnosis in patients presenting with uni-lateral neck swelling.

4) Adequate preoperative diagnosis is important for both diagnoses as well as for appropriate

\section{ACKNOWLEDGEMENTS}

The authors acknowledge the contribution of the Department of Radiology as well as Pathology of San Fernando General Hospital, Trinidad and Tobago for their contribution in reporting the CT scan of the Neck and histology report of this patient respectively.

\section{CONFLICTS OF INTEREST}

The authors have declared no conflicts of interest.

\section{AUTHOR'S DECLARATION}

The authors have nothing to disclose 


\section{PATIENT'S CONSENT}

Patient consent was obtained for publication of this article.

\section{REFERENCES}

[1] Wieneke J, Smith A. Paraganglioma: Carotid Body Tumor. Head Neck Pathol. 2009 Dec; 3(4):303-306. doi: 10.1007/s12105-009-0130-5.

[2] Irving R, Martin T. Paragangliomas. In Watkinson J, Gilbert R, editors. Stell and Maran's Textbook of Head and Neck Surgery and Oncology. Boca Raton, Florida: CRC Press, Taylor and Francis Group; 2012.

[3] Moore M, Netterville J, Mendenhall W, Isaacson B, Nussenbaum B. Head and Neck Paragangliomas: An Update on Evaluation and Management. Otolaryngol Head Neck Surg. 2016 February; 154(4). ):597-605. doi: 10.1177/0194599815627667. Epub 2016 Feb 9.

[4] Gad A, Sayed A, Elwan H, Fouad F, Eldin H, Khairy H, et al. Carotid Body Tumors: A Review of 25 years experience in diagnosis and management of 56 tumors. Annals of Vascular Diseases. 2014 August; 7(3).

[5] Duncan D, McDonald J. Chemodectoma(Nonchromaffin Paraganglioma) Of The Mediastinum. Annals of Surgery. Aug 1954.

[6] Mulligan, R.M. Chemodectoma in the dog(Abstr.). Am. J. Path., 26: 680-681,1950.

[7] Milner R., Babrowski T. Carotid Body Tumours. Thompson M., editor. Oxford Textbook of Vascular Surgery. Oxford, United Kingdom: Oxford University Press. 2016

[8] Singh D, Jaydip R, Rajani. Management for Carotid Body Tumors: A Single Center Experience. Indian J Vasc Endovasc Surg 2014;1:8-11

[9] Saldana MJ, Salem LE, Travezan R: High altitude hypoxia and chemodectomas. Hum Pathol. 1973, 4: 251-263.

[10] Leidenz FB, Bastos-Rodrigues L, Oliveira M, Mamede M, Sarquis M, Friedman E, de Marco L.Malignant phenotype and two SDHD mutations in a family with paraganglioma syndrome type 1.Genet Res (Camb). 2015 Mar 30;97:e3. doi: 10.1017/S0016672315000063 PMID: 25819804.

[11] Kaygusuz I1, Karlidag T, Keles E, Yalcin S, Yüksel K Carotid Body Tumor: Clinical Features. J Craniofac Surg. 2015 Oct;26(7):e586-9.

[12] Luna-Ortiz K, Rascon-Ortiz M, Villavicencio-Valencia V, Herrera-Gomez A. Does Shamblin's classification predict postoperative morbidity in carotid body tumors? A proposal to modify Shamblin's classification. Eur Arch Otorhinolaryngol. 2006 Feb; 263(2):171-5. Epub 2005 Jul 12.

[13] Lazar B Davidovic Vojko B Djukic Dragan M Vasic, Radomir P Sindjelic and Stevo $N$ Duvnjak. Diagnosis and treatment of carotid body paraganglioma: 21 years of experience at a clinical center of Serbia World Journal of Surgical Oncology20053:10 DOI: 10.1186/1477-7819-3-10January 2005Volume 41, Issue 1, Pages 56-61

[14] Chand P, Singh R, Singh B, Singla RL. Carotid Body Tumor Presenting as Parotid Swelling Misdiagnosed as Pleomorphic Adenoma: A Rare Presentation. Niger J Surg. 2015 Jul-Dec;21(2):157-8. doi: 10.4103/1117-6806.162588.

[15] Wang, S., Chiu K., Cheng P. Bilateral carotid body paragangliomas. CMAJ. 2011 Jun 14; 183(9): E606. doi: 10.1503/cmaj.092114 
[16] Budincevic H1, Piršic A, Bohm T, Trajbar T, Ivkošic A, Pavlovic T, Bielen I, SoldoButkovic S. Carotid Body Tumor as a Cause of Stroke. Intern Med. 2016;55(3):295-8. doi: 10.2169/internalmedicine.55.5350. Epub 2016 Feb 1

[17] Chamorro Sanchez A, Varela de Seijas E, Matesanz Matesanz J, Trapero VL. Carotid body tumor: unusual cause of transient ischemic attacks. Stroke. 1988 Jan;19(1):102-3.

[18] Fudim M1, Groom KL2, Laffer CL3, Netterville JL2, Robertson D4, Elijovich F Effects of carotid body tumor resection on the blood pressure of essential hypertensive patients.J Am Soc Hypertens. 2015 Jun;9(6):435-42. doi: 10.1016/j.jash.2015.03.006. Epub 2015 Mar 19.

[19] Da Silva D, O’Donnel S, Gillespie D, Goff J, Shriver C, Rich N. Malignant Carotid Body Tumor: a case report. J Vasc Surg. 2000 Oct; 32(4): 821-3.

[20] Pacheco-Ojeda L. Malignant carotid body tumors: report of three cases. Annals of Otology, Rhinology and Laryngology. 2001;110(1):36-40. doi: 10.1177/000348940111000107. [PubMed]

[21] Sajid MS, Hamilton G, Baker DM. A Multicenter Review of Carotid Body Tumour Management. Eur J Vasc Endovasc Surg. 2007 August; 34(2).

[22] Naik S, Shenoy A, Nanjundappa, Halkud R. Paragangliomas of the Carotid Body: Current Management Protocols and Review of Literature. Indian J Surg Oncol. 2013 September; 4(3).

[23] Power A, Bower T, Vrtiska T, Duncan A,Kalra M, Oderich G, Gloviczki P. Imaging Predictors of Cranial Nerve Injury in Carotid Body Tumor Resections. J Vasc Surg June 2012; Vol 55(6): Supp. 91S-92S.

[24] Straughan DM, Neychev VK, Sadowski SM, Ellis RJ, Thomas F, Patronas NJ, Pacak K, Kebebew E, Nilubol N. Preoperative Imaging Features are Associated with Surgical Complications Following Carotid Body Tumor Resection. World J Surg. 2015 Aug;39(8):2084-9. doi: 10.1007/s00268-015-3058-9. PMID: 25840820.

[25] Shamblin W. R., ReMine W. H., Sheps S. G., Harrison E. G., Jr. Carotid body tumor (chemodectoma). Clinicopathologic analysis of ninety cases. The American Journal of Surgery. 1971;122(6):732-739. doi: 10.1016/0002-9610(71)90436-3.

[26] Galyfos G, Stamatatos I,Kerasidis S, Stefanidis I, Giannakakis S, Kastrisios G, Geropapas G,Papacharalampous G, and Maltezos C.Multidisciplinary Management of Carotid Body Tumors in a Tertiary Urban Institution10. Int J Vasc Med. 2015; 2015: 969372. Published online 2015 Dec 9. doi: 10.1155/2015/969372

[27] Arya S., Rao V., Juvekar S., Dcruz A. K. Carotid body tumors: objective criteria to predict the Shamblin group on MR imaging. American Journal of Neuroradiology. 2008;29(7):1349-1 354. doi: 10.3174/ajnr.a1092.

[28] Lim J, Kim J, Kim S, Lee S. Surgical Treatment of Carotid Body Paragangliomas: Outcomes and Complications According to the Shamblin Classification. Clin Exp Otorhinolaryngol. 2010 June; 3(2).

[29] Law Y, Chan YC, Cheng SW. Surgical management of carotid body tumor - Is Shamblin classification sufficient to predict surgical outcome? Vascular. 2016 Jun 29. pii: 1708538116657504. [Epub ahead of print]

[30] Mayer R, Fruhwirth J, Beham A, Groell R, Poschauko J, Hackl A: Radiotherapy as adjunct to surgery for malignant carotid body paragangliomas presenting with lymph node metastases. Strahlenther Onkol. 2000, 176: 356-360. 